\title{
Yenidoğan yoğun bakım ünitesinde nozokomiyal infeksiyon etkenleri ve antibiyotik direnç özellikleri : Son bir yıllık deneyim
}

\author{
Nosocomial infection agents and antibiotic resistance profiles in neonatal intensive care unit : An experience of one year
}

\author{
Özgür Olukman*, Füsun Atlıhan, Gamze Gülfidan, Şebnem Çalkavur, İsmail Cengiz Öztürk
}

Dr. Behçet Uz Çocuk Hastalıkları ve Cerrahisi Eğitim ve Araştırma Hastanesi, İzmir

\begin{tabular}{|c|c|}
\hline \multicolumn{2}{|c|}{ MAKALE BİLGÍLERİ } \\
\hline \multicolumn{2}{|c|}{ Makale Geçmişi: } \\
\hline Geliş & $27 / 10 / 2009$ \\
\hline Kabul & 09 / 02 / 2010 \\
\hline \multicolumn{2}{|c|}{ * Yazışma Adresi: } \\
\hline \multicolumn{2}{|c|}{ Özgür OLUKMAN } \\
\hline \multicolumn{2}{|c|}{$\begin{array}{l}\text { 108/32 sk. no:22 d:11 Adnan Süvari Mah } \\
\text { Esenyal, İzmir }\end{array}$} \\
\hline E-post & olukman2002@yahoo.com \\
\hline
\end{tabular}

\section{Anahtar Kelimeler:}

Nozokomiyal İnfeksiyon

Antibiyotik Direnci

Yenidoğan

Yoğun Bakım

Ampirik Tedavi

Aktif Sürveyans

\section{Key Words :}

Nosocomial Infection

Antibiotic Resistance

Newborn

Intensive Care

Empirical Treatment

Active Surveillance

\section{ÖZET}

Nozokomiyal infeksiyonlar (NKİ) yenidoğanlarda anlamlı mortalite ve morbidite nedenidir. Özellikle düşük doğum tartılı yenidoğanlar NKI'lar açısından yüksek riskli olduklarından etkenlerin ve antimikrobiyal direnç özelliklerinin bilinmesi ampirik tedavi seçimleri açısından önemlidir. Çalışmamızda ünitemizde NKİ'a yol açan mikroorganizmaların ve antibiyotik duyarlılıklarının saptanması amaçlanmıştır. Ünitemizde Ocak 2008-Ocak 2009 tarihleri arasında hastaya dayalı aktif sürveyans yöntemiyle saptanan NKI'lar, üreyen etkenler ve antibiyotik duyarlılıkları prospektif olarak değerlendirildi. Ünitemizde yatan 372 hastanın 4'ü term, 12'si preterm olmak üzere toplam 16'sında (\%4,3) 30 NKİ atağı saptand. Hastane infeksiyon hızımız \%8,07 idi. NKİ sıklığı termlerde \%25, pretermlerde \%75'di. Kan dolaşımı infeksiyonu \%43'le ilk sıradaydı. En sık izole edilen etkenler Pseudomonas aeruginosa (\%20), Klebsiella pneumoniae (\%20) ve Candida türleriydi (\%20). Gram negatif etkenler $\% 44$, gram pozitifler $\% 36$, Candida türleri $\% 20$ oranındaydı. Gram negatif etkenlerde ampisilin ve aminoglikozid direnci $\% 100$, sefalosporin direnciyse $\% 92$ bulundu. Gram negatif enterik basillerde genişletilmiş spektrum betalaktamaz (GSBL) pozitifliği \%.100'dü. Gram pozitif etkenlerden stafilokok türlerinde metisilin direnci \% 80'iken, glikopeptid direnci görülmedi. Genel ölüm hızı \%1,8'di. Ölen term bebeklerde hipoksik iskemik ensefalopati, pretermlerdeyse respiratuar distres sendromu, nekrotizan enterokolit ve pnömotoraks tanıları mevcuttu. Sonuç olarak başta el yıkama olmak üzere infeksiyon kontrol kurallarına tam olarak uyulması, aktif sürveyans çalışmaları ve akılcı antibiyotik kullanımıyla dirençli NKİ sıklığının azaltılabileceği düşünülmektedir.

J. Exp. Clin. Med., 2009; 26:72-76

\begin{abstract}
Nosocomial infections are responsible for significant mortality and morbidity in hospitalized newborns. Especially very low birth weight infants are accepted to be under high risk. For this reason it is important to know the pathogenic agents and their antimicrobial resistance profiles in a neonatal intensive care unit when choosing an empiric antibiotic treatment. In this study we aimed to determine the nosocomial pathogens and their antibiotic sensitivity patterns in our unit. Between January 2008 and January 2009 we performed a prospective study to determine hospital-acquired infections in our unit, to assess pathogenic culture results and to evaluate antibiotic susceptibility patterns by using patient-based active surveillance system. During the study period we hospitalized 372 newborn babies in our unit and we ascertained 30 nosocomial infection attacks in $16(4.3 \%)$ infants. Our overall hospital infection rate was $8.07 \%$. Premature infants had a nosocomial infection rate of $75 \%$, whereas mature infants had an infection rate of $25 \%$. Most nosocomial infections were bloodstream infections (43\%). Most common causitive pathogens were Pseudomonas aeruginosa (20\%), Klebsiella pneumonia (20\%) and Candida species (20\%). We found that gram negative agents were responsible for $44 \%$, gram positive agents were responsible for $36 \%$ and candida species were responsible for $20 \%$ of nosocomial infections. Ampicilline and aminoglycoside resistance ratios were $100 \%$ in gram negative agents. On the other hand cephalosporine resistance ratio was found to be $92 \%$. Expanded spectrum betalactamase positivity was detected as $100 \%$ in gram negative enteric bacilli. Methycilline
\end{abstract}


resistance ratios in coagulase-negative staphylococci was $80 \%$. There was no apparent resistance against glycopeptides among gram positive agents. The overall mortality rate was calculated as $1.8 \%$. In mature infants hypoxic ischemic encephalopathy, in premature infants respiratory distress syndrome, necrotising enterocolitis and pneumothorax were the underlying causes which led to death. In conclusion hand hygiene standing first on the list, all nursery personnel should strictly obey preventive principles against nosocomial infections. Active surveillance and rational antibiotic usage may be helpful in decreasing the frequency of resistant nosocomial infections.

J. Exp. Clin. Med., 2009; 26:72-76

(C) 2009 OMÜ Tüm Hakları Saklıdır.

\section{Giriş}

Nozokomiyal infeksiyonlar (NKİ) yenidoğan bebek bakımında sağlanan tüm gelişmelere rağmen Yenidoğan Yoğun Bakım Ünitelerinde (YYBÜ) önemli bir mortalite ve morbidite nedeni olmaya devam etmektedir (Gaynes ve ark., 1996). Özellikle düşük doğum tartılı yenidoğanlar bağışıklık sistemlerinin göreceli olarak az çalışması ve maternal kaynaklı immunglobülinlerden yoksun olmaları nedeniyle NKI' lar açısından yükssek risk taşırlar. Ayrıca bu bebeklerin maruz kaldığı uzun süreli mekanik ventilasyon, santral kateter uygulamaları, uzun süreli parenteral beslenme, geniş spektrumlu antibiyotik ve steroid kullanımı gibi diğer faktörler de NKİ gelişimini kolaylaştırır (Gaynes ve ark., 1996; Chan ve ark., 2001; Zafar ve ark., 2001). Öte yandan NKİ gelişen bebeklerin hastanede kalış süreleri uzar ve bunlarla ilgili sağlık harcamaları da artar (Harris ve Goldmann, 2001; Zafar ve ark., 2001). Bu nedenle NKI etkenlerinin ve antimikrobiyal direnç özelliklerinin bilinmesi ampirik tedavi seçimleri açısından hayati önem taşır. Çalışmamızda ünitemizde NKİ'a yol açan mikroorganizmaların ve antibiyotik duyarlılıklarının saptanması amaçlanmıştır.

\section{Araştırma Yöntemi}

Dr. Behçet Uz Çocuk Hastanesi YYBÜ'sinde Ocak 2008-Ocak 2009 tarihleri arasındaki bir yıllık dönemde hastaya dayalı aktif sürveyans yöntemiyle saptanan NKI'lar, üreyen etkenler ve antibiyotik duyarlılıkları prospektif olarak değerlendirildi. Bunun için YYBÜ'de yatan tüm hastalar enfeksiyon kontrol hekimi tarafından her gün düzenli olarak ziyaret edildi. Hastalara ait tüm klinik ve laboratuar veriler, almakta oldukları antibiyotikler, altta yatan risk faktörleri, mekanik ventilasyon tedavisi alan hastalarda ventilatöre bağlı kaldıkları gün sayısı, kateteri olan hastalarda ise kateterin takılı kaldığı gün sayısı kayıt altına alındı. Bu veriler kültür üremeleri ile kıyaslanarak hastalarda klinik veya laboratuarla desteklenmiş NKİ gelişip gelişmediği değerlendirildi. Gerektiğinde kültür antibiyogram sonuçlarına göre hastaların almakta olduğu antibiyotik tedavileri yeniden düzenlendi. Tedaviye alınan yanıtlar klinik yanıt, indirekt laboratuar yanıtları ve kültür yanıtları olarak 3 kategoride incelendi. Kan kültürleri BACTEC 9240 Otomatize Kültür Sistemi’nde çalışıldı.
Diğer kültür örnekleri konvansiyonel yöntemlerle işleme alınd. Mikroorganizma identifikasyonu ve antimikrobiyal duyarl111k testleri VITEK-2 Compact Otomatize Sistem'de ( bioM-rieux, Fransa) çalışıldı.

\section{Sonuçlar}

Ünitemizde yatan 372 hastanın 4'ü term, 12'si preterm olmak üzere toplam 16 'sında $(\% 4,3) 30$ NKİ atağ 1 saptand1. Hastane infeksiyon hızımız \%8,07 olarak belirlendi. NKİ s1klığ 1 termlerde $\% 25$, pretermlerde $\% 75$ bulundu. Kan dolaşımı infeksiyonu \%43 ile ilk sırayı alırken bunu deri, göz ve kulak-burun-boğazın yüzeyel infeksiyonları (\%27) izlemekteydi. İnfeksiyon yerlerine göre dağllım Tablo 1'de özetlenmiştir.

Tablo 1. İnfeksiyon yerlerine göre dağılım.

\begin{tabular}{|l|l|l|}
\hline İnfeksiyon yeri & Sayı & $\begin{array}{c}\text { Oran } \\
\%\end{array}$ \\
\hline Kan dolaşımı infeksiyonu & 13 & 43 \\
\hline Deri, göz, kulak, burun, boğazın yüzeyel infeksiyonları & 8 & 27 \\
\hline Ventilatörle ilişkili pnömoni & 4 & 13 \\
\hline Gastrointestinal sistem infeksiyonları & 2 & 7 \\
\hline Merkezi sinir sistemi infeksiyonları & 2 & 7 \\
\hline Üriner sistem infeksiyonları & 1 & 3 \\
\hline Toplam & 30 & 100 \\
\hline
\end{tabular}

İnvaziv araç ilişkili infeksiyon oranlarımız değerlendirildiğinde ventilatör ilişkili pnömoni hızımız \%1,89 olarak belirlendi (Tablo 2). Santral venöz kateter veya üriner kateter kullanılan hiçbir hastada kateter ilişkili infeksiyon gelişmedi.

Tablo 2. Ventilatör ilişkili pnömoni hızı.

\begin{tabular}{|l|c|c|c|c|c|c|}
\hline $\begin{array}{c}\text { DOĞUM } \\
\text { TARTISI }\end{array}$ & $\begin{array}{c}\text { HASTA } \\
\text { SAYISI }\end{array}$ & $\begin{array}{c}\text { HASTA } \\
\text { GÜNÜ }\end{array}$ & $\begin{array}{c}\text { VENTILATÖR } \\
\text { GÜNÜ }\end{array}$ & $\begin{array}{c}\text { VIP } \\
\text { SAYISI }\end{array}$ & $\begin{array}{c}\text { VENTILATÖR } \\
\text { KULLANIM } \\
\text { ORANI }\end{array}$ & $\begin{array}{c}\text { VIP } \\
\text { HIZI }\end{array}$ \\
\hline$\leq 1000$ gram & 77 & 955 & 660 & 2 & 0,69 & 3,03 \\
\hline $1001-1500$ gram & 95 & 647 & 394 & 1 & 0,61 & 2,54 \\
\hline $1501-2500$ gram & 93 & 631 & 445 & 1 & 0,71 & 2,25 \\
\hline$>2500$ gram & 107 & 940 & 622 & 0 & 0,66 & 0 \\
\hline TOPLAM & 372 & 3173 & 2121 & 4 & 0,67 & 1,89 \\
\hline
\end{tabular}

En s1k izole edilen etkenler P. aeruginosa (\%20), K. pneumoniae (\%20) ve Candida türleriydi (\%20). Gram negatif etkenler $\% 44$, gram pozitifler $\% 36$, Candida türleri ise $\% 20$ oranında tespit edildi. Candida üremelerinin 
Tablo 3. Etken patojenlere göre dağılım.

\begin{tabular}{|l|l|l|l|}
\hline & ETKEN & SAYI & ORAN (\%) \\
\hline Gram negatif & & 11 & 44 \\
\hline \multirow{5}{*}{ Gram pozitif } & P.aeruginosa & 5 & 20 \\
\cline { 2 - 4 } & K.pneumoniae & 5 & 20 \\
\cline { 2 - 4 } & E.meningoseptica & 1 & 4 \\
\cline { 2 - 4 } & & 9 & 36 \\
\cline { 2 - 4 } & Viridan streptokok & 3 & 12 \\
\cline { 2 - 4 } & Koagülaz negatif stafilokok & 2 & 8 \\
\cline { 2 - 4 } & S.aureus & 2 & 8 \\
\cline { 2 - 4 } & Enterokoklar & 2 & 8 \\
\hline Mantarlar & & 5 & 20 \\
\hline & C.parapsilosis & 3 & 12 \\
\cline { 2 - 4 } & C.albicans & 2 & 8 \\
\hline Toplam & & 25 & 100 \\
\hline
\end{tabular}

\%60’`1 albicans dışı maya türlerine aitti (Tablo 3).

Gram negatif etkenlerde ampisilin ve aminoglikozid direnci $\% 100$, sefalosporin direnciyse $\% 92$ bulundu. Pseudomonas üreyen 3 hastada yüksek düzey betalaktam ve karbapenem direnci vard. Gram negatif enterik basillerde genişletilmiş spektrum betalaktamaz (GSBL) pozitifliğinin \%100 olduğu tespit edildi. Gram pozitif etkenlerden stafilokok türlerinde metisilin direnci $\% 80$ oranında bulunurken, glikopeptidlere hiç direnç olmadığı görüldü. $\mathrm{Bu}$ veriler hastalarımızın klinik seyri, infeksiyonun indirekt laboratuar göstergeleri ve mortalite hızımız ile kıyasland1. Yüksek düzey betalaktam ve karbapenem dirençli Pseudomonas üreyen 3 hasta hariç, tüm hastalarda tam tedavi başarısı sağlandı. Bu nedenle tercih edilen ampirik antibiyotik tedavimizde değişiklik yapılmadı. Ancak $12 \pm 7,04$ gün olan ortalama antibiyotik kullanım süremiz $\% 42$ oranında kısaltılarak $7 \pm 4,06$ güne düşürüldü.

Term bebeklerin \%1,6's1, pretermlerin \%2,1'i kaybedildi. Genel ölüm hızı \%1,8 idi. Ölen term bebeklerde evre 3 ağır hipoksik iskemik ensefalopati, pretermlerdeyse respiratuar distres sendromu, nekrotizan enterokolit ve pnömotoraks tanıları mevcuttu.

\section{Tartışma}

Son y1llarda neonatolojideki gelişmeler çok düşük doğum ağırlıklı yenidoğanların yaşatılmasına olanak sağlarken, hastane kaynaklı infeksiyonların sıklığının artmasına yol açmıştır.

NKİ gelişme riski gestasyon yaşı ve doğum tartısı ile ters ilişkilidir. Öyle ki NKİ sıklığı term yenidoğanların bulunduğu servislerde yüz yenidoğanda 0,3-1,7 arasındadır (Gaynes ve ark., 1996; Chan ve ark., 2001; Zafar ve ark., 2001). Preterm yenidoğan servislerinde ise doğum tartıs1 1500 gramın altında olanlarda siklık \%15-20, 1000 gramın altında olanlarda ise \%40 olarak bildirilmektedir (Harris ve Goldmann, 2001). Bunlara göre YYBÜ'de sıklık yüz yatan hastada 1,8-39,8 arasında değişmektedir. Ünitemizde NKİ sıklığ 1 termlerde $\% 2,2$, pretermlerde $\% 6,3$ olarak belirlendi. Ortalama gestasyon haftası 32 hafta, doğum ağırlığı 1550 gram bulundu. Hastane infeksiyon hızımız ise $\% 8,07$ olarak hesapland.
Prematürite ve düşük doğum ağırlığının dışında infeksiyon riskini arttıran diğer faktörler uzun süren mekanik ventilasyon, santral kateter kullanımı ve diğer invaziv enstrümantasyonlar, uzun süreli geniş spektrumlu antibiyotik tedavileri, uzun süreli parenteral beslenme, anne sütü yerine mama ile beslenme, hasta yoğunluğunun artmış olması, yetersiz sağlık ekibi ve infeksiyon kontrol önlemlerine özen gösterilmemesi olarak sıralanabilir (Brodie ve ark., 2000; Kawagne ve ark., 2001). Ünitemizde NKİ tespit edilen hastalarımızda özellikle mekanik ventilasyon, santral ve üriner kateter kullanımı gibi invaziv araç uygulamaları, parenteral beslenme ve geniş spektrumlu antibiyotik kullanımı ön plandaydı.

NKI'larda infeksiyonun yeri en s1k kan dolaşımıdır (bakteremi). Bunu nozokomiyal pnömoni ve gastrointestinal infeksiyonlar izler (Raymond ve ark., 2000). Ünitemizde de kan dolaşımı infeksiyonu \%43'le ilk sıradaydı. Ancak literatürün aksine deri, göz ve kulak-burun-boğazın yüzeyel infeksiyonları (göbek, konjunktiva, dış kulak, farinks ve burun sürüntü kültürlerinde üreme ile tespit edilen omfalit, konjunktivit, eksternal otit, farenjit gibi infeksiyonlar) (\%27) ikinci sırada, ventilatör ilişkili pnömoni (\%13) ise üçüncü sırada yer almaktaydı. Burada yüzeyel sürüntü kültürlerindeki üremeler, klinik ve indirekt laboratuar verileri ile kıyaslanarak, kolonizasyonlardan ayırt edildi. Özellikle ventilatör ilişkili pnömoni hızımızın 1,89 gibi oldukça başarılı bir değerde olması enfeksiyon kontrol önlemlerinin (eğitim çalışmaları, sterilizasyondezenfeksiyon kurallarına uyum, yerinde izolasyon önlemleri, el hijyenine dikkat, uygun sayı ve nitelikte personel istihdamı) titizlikle uygulanması ve başarılı aktif sürveyansa bağlandı.

NKI'dan sorumlu mikroorganizmalar yıllar içinde olduğu kadar, ülkeler hatta üniteler arasında da değişkenlikler göstermektedir. Son yıllarda en s1k sorumlu tutulan mikroorganizmalar Koagülaz Negatif Stafilokoklar ve gram negatif enterik basillerdir (Raymond ve ark., 2000). Doğum tartıs1 1500 gramın altında olan yenidoğanlarda $\% 70$ oranında gram pozitif, $\% 18$ oranında gram negatif organizmalar ve $\% 12$ oranında mantarlar NKİ'dan sorumludur (Stoll ve ark., 2002). Oysa kültür pozitif olduktan sonraki 48 saat içerisinde görülen hızlı ölümlerde \%69 oranında gram negatif organizmalar sorumludur (Karlowicz ve ark., 2000). Biz ünitemizde gram negatif etkenlere bağlı NKİ'ları \%44 oranında bulurken, gram pozitiflerle gelişen infeksiyonların sıklığını \%36 olarak tespit ettik. Gram pozitif etkenlerden Koagülaz Negatif Stafilokoklar ve S. aureus eşit sıklıkta görülmekteydi (\%8). Literatür bilgisinin aksine NKI'a bağlı ölüm gelişen gerek term, gerekse de preterm tüm vakalar değerlendirildiğinde gram pozitif (\%43) ve gram negatif (\%43) etkenlerin eşit sıklıkta olduğu görüldü. Ölümlerin geriye kalan \%14'ünde ise candida türleri izole edilmişti.

YYBÜ'lerinde zaman içinde NKİ etkenlerinin antimikrobiyal direnç özelliklerinin değerlendirilmesi oldukça önemlidir. Çünkü NKİ'ların \%50-60'ı dirençli bakteri 
suşlarıyla gelişir (Adams-Chapman ve Stoll, 2002). Son yıllarda özellikle metisiline dirençli stafilokoklar, vankomisin dirençli enterokoklar ve bir çok antibiyotiğe dirençli gram negatif bakteriler YYBÜ'lerinde ciddi sorun haline gelmiştir. Ünitemizde birinci basamak ampirik tedavide sulbaktam-ampisilin + aminoglikozid (netilmisin) veya ampisilin +3 .kuşak sefalosporin (sefotaksim) tercih edilmektedir. İkinci basamak ampirik tedavide ise glikopeptid + aminoglikozid (netilmisin veya amikasin) veya glikopeptid +3 . kuşak sefalosporin (sefotaksim) kullanılmaktadır. Eğer menenjit düşünülmüyorsa veya daha önce aminoglikozid kullanılmışsa karbapenem veya piperasilintazobaktam tercihleri yapılmaktadır. Çalışmamız sırasında NKI'a sebep olan gram negatif basillerde GSBL pozitifliğinin \%100 olduğunu gördük. Bu etkenlerde ampisilin ve aminoglikozid direncinin $\% 100$, sefalosporin direncinin ise $\% 92$ düzeyinde olduğunu saptadık. Pseudomonas üreyen 3 hastada yüksek düzey betalaktam ve karbapenem direnci geliştiğini tespit ettik ve bu hastalardan ikisini izlemde kaybettik. Öte yandan gram pozitif etkenlerden stafilokok türlerinde metisilin direncini $\% 80$ oranında bulurken, glikopeptidlere hiç direnç olmadığını saptadık.

Ünitemizde en sık üretilen NKİ etkenlerinin gram negatif mikroorganizmalar olması ve bu etkenlerin ampisilin, aminoglikozid ve sefalosporin dirençlerinin yüksek olması nedeniyle özellikle birinci basamak ampirik tedavide tercih ettiğimiz antibiyotik tedavisini yeniden gözden geçirdik. Burada Listeria monocytogenes'in yenidoğan döneminde ağır sepsis ve menenjitle seyretmesi, tedavisinde tek başına ampisilinin etkili olması ve kültür ortamında uzun sürede ve zahmetli üremesi nedeniyle ampisilini ampirik tedavi protokolünden çıkarmayı düşünmedik. Öte yandan aminoglikozid olarak düşük toksisitesi nedeniyle tercih ettiğimiz netilmisini ikinci basamakta yer alan karbapenemlerle değiştirmeyi düşündüysek de, bu antibiyotikle ilgili in-vitro ve in-vivo sonuçların uyumsuz olduğu kanısına vardık. Şöyle ki; mikroorganizma identifikasyonu ve antimikrobiyal duyarlılık testleri için kullandığımız VITEK-2 Compact Otomatize Sistem'de gram negatif enterik basiller panelinde (AST-N090 ve AST-N091) aminoglikozid olarak yalnızca amikasin ve gentamisin çalışılmaktadır. Bu nedenle netilmisin duyarlılığına disk difüzyon yöntemiyle bakılmaktadır. Doğal olarak bu yöntemde MİK (minimum inhibitör konsantrasyon) değerleri ölçülemediğinden direnç düzeyleri konusunda sağlıklı yorum yapılamamaktadır. Başka bir deyişle elde ettiğimiz netilmisin direncinin düşük düzeyde mi, yoksa yüksek düzeyde mi olduğu konusunda sayısal verilere ulaşılamamıştır. Ancak yüksek düzey betalaktam ve karbapenem dirençli pseudomonas üreyen 3 hastamız dışında tüm hastalarımızın klinik seyrinin çok iyi olması, infeksiyonun indirekt laboratuar göstergelerinin hizla düzelmesi ve son olarak mortalite hızımızın düşük olması nedeniyle netilmisin direncinin sandığımız kadar yüksek olmadığını düşündük. $\mathrm{Bu}$ nedenle uygunsuz tedavi oranımız in-vitro parametrelere göre yüksek görünse de, in-vivo değerlendirmede daha düşük oranlara sahip olduğumuzu düşünerek ampirik tedavi tercihlerimizi değiştirmedik. Öte yandan gram pozitif etkenlerden stafilokok türlerinde glikopeptidlere hiç direnç olmamasını, ampirik olarak başlanan tedavinin kültürlerde üreme olmadığının öğrenildiği en erken dönemde kesilmesine bağladık. Öyle ki bu durumu, 12 $\pm 7,04$ gün olan ortalama antibiyotik kullanım süremizi $7 \pm 4,06$ güne düşürmemizin bir yansıması olarak değerlendirmek mümkündür. Böylece bu çalışmadan çıkarılan en önemli sonuçlardan birisi, başlanan ampirik antimikrobiyal tedavinin eğer kültürde üreme yoksa mümkün olan en kısa süre içinde (ilk 48-72 saat içinde) sonlandırılması olmuştur. Bu durumun önümüzdeki yıllarda gelişecek NKİ oranlarına olumlu katkı sağlayacağı düşünülmektedir.

NKI'lara bağlı mortalite ve morbidite oranları da gestasyon yaşı ve doğum tartısı ile ters ilişkilidir. Literatürde mortalite oranları \%1,5-30 arasında değişmektedir (Raymond ve ark., 2000; Karlowicz ve ark., 2000; Stoll ve ark., 2002). Özellikle gestasyon yaş1 32 haftadan ve dogum tartıS1 1500 gramdan düşük olan bebeklerde mortalite oranları daha yüksek bulunmuştur (Stoll ve ark., 1996). Gestasyon haftasına göre altta yatan bazı hastalıkların varlığının da mortalite oranlarını artırdığı gösterilmiştir. Nitekim ünitemizde NKİ'a bağlı genel ölüm hızını \%1,8 olarak tespit ettik. NKİ gelişen term bebeklerin \%1,6'sını, pretermlerin ise $\% 2,1$ 'ni kaybettik. Term bebeklerde oranın bu denli yüksek olması altta yatan 3.evre ağır hipoksik iskemik ensefalopati ile ilişkili bulundu. Pretermlerdeyse mevcut respiratuar distres sendromu, nekrotizan enterokolit ve pnömotoraks gibi patolojilerin ölüm oranını $\operatorname{artırdığ~} 1$ düşünüldü.

Sonuç olarak yenidoğan bebeklerde NKI'lar hem morbidite ve mortalite, hem de hastane maliyetleri açısından önemli bir problem olmaya devam edecektir. Başta el y1kama olmak üzere infeksiyon kontrol kurallarına tam olarak uyulması bu tür infeksiyonların gelişimini azaltabilir (Kilbride ve ark., 2003; Adams-Chapman ve Stoll, 2005; Perk, 2008). Öte yandan YYYBÜ'lerinde ak1lc1 antibiyotik kullanımı, mümkün olduğu kadar dar spektrumlu antibiyotiklerin tercih edilmesi, geniş spektrumlu antibiyotiklerin ciddi enfeksiyonlara saklanması, kültür sonuçlarına göre tedavilerin erken dönemde sonlandırılması, proflaktik antibiyotik kullanımından kaçınılması ve ünitelerin kendi NKİ etkenlerini ve antibiyotik duyarlılık profillerini belirleyerek hareket etmesi bu büyümekte olan sorunu kontrol altına alınabilir.

\section{KAYNAKLAR:}

Adams-Chapman, I., Stoll, B. J., 2002. Prevention of nosocomial infections in the neonatal intensive care unit. Curr. Opin. Pediatr. $14,157-164$.

Adams-Chapman, I., Stoll, B. J., 2005. Nosocomial Infection in the Nursery. In Avery's Diseases of the Newborn, H. W. Taeusch, R. A. Ballard and C. A. Gleason, eds. Elsevier, Philadelphia, pp. 578-594. 
Brodie, S. B., Sands, K. E., Gray, J. E., Parker, R. A., Goldmann, D. A., Davis, R. B., Richardson DK., 2000. Occurence of nosocomial bloodstream infections in six neonatal intensive care units. Pediatr. Infect. Dis. J. 19, 56-62.

Chan, K., Ohlsson, A., Synnes, A., Lee D. S., Chien, L. Y., Lee, S. K., 2001. Survival, morbidity and resource use of infants of 25 weeks gestational age or less. Am. J. Obstet. Gynecol. 185, 220-226.

Gaynes, R. P., Edwards, J. R., Jarvis, W. R., Culver, D. H., Tolson, J. S., Martone, W. J., 1996. Nosocomial infections among neonates in high-risk nurseries in the United States. Pediatrics 98, 357-561.

Harris, J. S., Goldmann, D. A., 2001. Infections acquired in the nursery; epidemiology and control. In Infectious Diseases of the Fetus and Newborn Infant, J. S. Remington and J. O. Klein, eds. W. B. Saunders, Philadelphia, pp. 1371-1418.

Karlowicz, M. G., Buescher, S., Surka, A. E., 2000. Fulminant late-onset sepsis in a neonatal intensive care unit, 1988-1997, and the impact of avoiding empiric vancomycin therapy. Pediatrics 106, 1387-1390.

Kawagne, J. Y., Segre, C. A., Pereira, C. R., Cardoso, M.F., Silva, C. V., Fukushima, J. T., 2001. Risk factors for nosocomial infections in critically ill newborns: a 5 year prospective cohort study. Am. J. Infect. Control. 29, 109-114.

Kilbride, H. W., Powers, R., Wirtschafter, D. D., Sheehan, M. B., Charsha, D. S., LaCorte, M., Finer N, Goldmann DA., 2003. Evaluation and development of potentially better practices to prevent neonatal nosocomial bacteremia. Pediatrics 111, 505-518.

Perk, Y., 2008. Yenidoğan yoğun bakım enfeksiyonları; korunma ve kontrol. Hastane Enfeksiyonları Korunma ve Kontrol Sempozyum Dizisi. 60, 137-141.

Raymond, J., Aujard, Y., and the European Study Group., 2000. Nosocomial infections in pediatric patients: a European multicenter prospective study. Infect. Control. Hosp. Epidemiol. 21, 260-263.

Stoll BJ, Gordon T, Korones SB, Shankaran S, Tyson JE, Bauer CR, Fanaroff AA, Lemons JA, Donovan EF, Oh W, Stevenson DK, Ehrenkranz RA, Papile LA, Verter J, Wright LL., 1996. Late- onset sepsis in very low birth weight neonates: a report from the National Institute of Child Health and Human Development Neonatal Research Network. J. Pediatr. 129, 63-71.

Stoll, B. J., Hansen, N., Fanaroff, A. A., Wright, L. L., Carlo, W. A., Ehrenkranz, R. A., 2002. Late onset sepsis (LOS) in VLBW neonates: the experience of the NICHD Neonatal Research Network. Pediatrics 110, 258-291.

Zafar, N., Wallace, C. M., Kieffer, P., Schroeder, P., Schootman, M., Hamvas, A., 2001. Improving survival of vulnerable infants increases neonatal intensive care unit nosocomial infection rate. Arch. Pediatr. Adolesc. Med. 155, 1098-1104. 